atory. He took samples under water in the infralittoral and littoral zones during high water, by diving, "using nothing but glasses, flippers and a belt with pieces of lead fixed to it". Eight weeds were chosen, and one sample of Gelidium corneum yielded the astonishing number of 2,818 animals per gram of dry weed, including 600 Nematodes and 1,864 specimens of Lascea rubra. Observations under water, using a modified frogman apparatus, were also made by Mr. R. Bainbridge, who describes the swimming habits of Calanus and Sagitta.

The necessity to control the bacterial contamination of mould-free phytoplankton cultures led Mr. C. P. Spencer to experiment with the antibiotics penicillin and streptomycin, the former being the more effective in keeping the culture pure. Miss B. Ross studied the changes in chemical composition at various ages of Himanthalia elongata, and found that any estimate of the chemical composition at different seasons should be correlated with the size of the vegetative buttons and thongs. Cultures of sixteen species of the smaller marine algæ, including seven flagellates, were prepared by Mr. R. W. Butcher, whose paper is illustrated by coloured figures of all the species. Finally, the first number of Vol. 31 concludes with an interesting account by Dr. D. P. Wilson of the aquarium and sea-water circulatory system at the Plymouth Laboratory.

In the second number, Dr. H. G. Vevers describes improvements in his apparatus for photographing the sea floor, whereby the camera is set at $1 \mathrm{~m}$. from the ground and records an area of $50 \mathrm{~cm} . \times 50 \mathrm{~cm}$. thus producing better definition. As the result of his surveys, Dr. Vevers estimates that near Looe there is a population of Ophiothrix fragilis at least two miles long and half a mile broad, at a density of 392,000 per acre. North-west of the Eddystone the population is even greater and reaches $1 \cdot 3$ million per acre. In both cases, tidal streams probably bring suspended food to the crowded beds, and the scavenging work of these brittle stars, whether of detritus or of sinking matter, must be considerable.

Dr. R. B. Pike has worked on the biology of the prawn Pandalus bonnieri, which is a dicecious species living in deep water. Breeding occurs from the end of October for from six to eight weeks, and the young leave the berried female from February to April in the following year, metamorphosing in June. Sexual maturity is reached in eighteen months. The maximum life-span is four years; but few live beyond three years in the Clyde area.

Dr. J. S. Alexandrowicz studied the muscle receptor organs in the Paguridæ, and Mr. Graham Hoyle the response mechanism in the Ascidians, Phallusia mammillata and Ascidiella aspersa. Prof. J. E. Harris has kept records of the breeding condition of dogfish supplied to the University of Bristol from the Ilfracombe area, and concludes that spawning starts in November and continues until July. A Fulbright scholar from Miami, Mr. R. F. Hutton, has named a cercaria from the cockle, Cercaria fulbrighti, and gives a full description of it and other parasites from this lamellibranch.

To the biological indicators of water movements in the English Channel (Sagitta and Muggicea spp.), Dr. L. H. N. Cooper suggests adding the boar fish, Capros aper (L.), the occurrence of which coincides with that of Muggicea kochi, indicating movement of water from the south-west area of the continental slope towards Plymouth, after a period of strong south-west winds succeeded by calm weather.
Hydrographical observations are recorded by Dr. W. R. G. Atkins and Miss P. Jenkins, and on the reaction of marine animals to ultra-violet light in conjunction with echo sounders by R. E. Craig and I. G. Baxter, who hope that further work will produce results of practical importance to the fishing industry.

In their first paper in a series on the vitamin A and carotenoid content of invertebrates, Mr. L. R. Fisher and Drs. S. K. Kon and S. Y. Thompson describe an investigation of the various Crustacea from the British coasts, particularly the Euphausiids, Meganyctiphanes norvegica and Euphausia superba, the krill upon which some whales feed. These contained large quantities of vitamin A, 90 per cent of which was in their large eyes, together with a high proportion of their astaxanthin. No carotene was present. The vitamin A concentration was lower in decapods, absent in the copepod Calanus finmarchicus, amphipods, isopods and Cladocera. By consuming krill, a baleen whale may take in one ton of vitamin $\mathrm{A}$, to be stored in the liver, which would yield about $2,000,000$ I.U.

The volume ends with the report of the Council of the Marine Biological Association. It is pleasant to note that for the first time the Association will be able to have a vessel specially built as a research ship. Membership has increased by 47 to 659 .

N. B. Eales

\section{PATTERNS OF SPRING MIGRATION}

IN 1950 and 1951 the British bird observatories exchanged information about the occurrences of selected species of birds. A study of this collated information by R. K. Cornwallis appears to throw some light on the pattern of migration to and through the British Isles in spring (British Birds, 45, No.9; September 1952).

The simple conception of this pattern of spring migration is one of a south-to-north movement. The birds, it is assumed, enter England at points along the south coast and proceed northwards until they either reach their breeding-grounds in Britain, or, if they do not remain to breed, strike north-west to Iceland or north-east to Scandinavia from our northern coasts. This is often assumed in ornithological writings to be what happens, though the subject is a neglected one.

Not all the facts, however, appear to fit this simple pattern. For example, certain birds which breed in Scandinavia and occur in Britain both as summer residents and as passage migrants were recorded on spring migration in 1950 in greater numbers at the more northerly bird observatories, the numbers decreasing regularly with each more southerly observatory in turn (pied flycatcher, garden warbler, lesser whitethroat, common redstart).

It is common, too, when waves of birds are recorded at the east-coast observatories, for these to occur on approximately the same date at all of them and not progressively later at the more northerly stations (redstarts, pied flycatchers, fieldfares and ring ouzels). Moreover, the greatest numbers of some birds are often observed, particularly at east-coast stations, on dates when British breeding birds of the same species have already started nesting, even when the breeding-ground lies farther north than the observatory.

A fourth fact is that at Gibraltar Point the direction of diurnal migration in the spring, as well as in the 
autumn, is almost invariably to the south-west. At Cley it is from east to west. In north Lincolnshire it is more orthodox, being north-west along the south bank of the Humber, but at Spurn both northward and southward movements are seen.

The most likely explanation of these facts seem to be that, as well as receiving migrants in accordance with the simple south-north pattern, the British Isles also receive "drift-migrants" which, aiming for their Scandinavian breeding-grounds, are drifted westwards across the North Sea by the wind.

It is likely that drift of this kind affects nocturnal migrants much more than it does diurnal ones, for they, presumably, must rely for navigation principally on "preferred direction" and not on coastal and other "guiding-lines", and are therefore more likely to be sent off-course by the invisible forces of wind-drift. The directions of diurnal migration at Cley and Gibraltar Point, however, seem to indicate that some diurnal migrants are also subject to drift of the same kind.

Drift-migration of this type explains the coincidence of dates on which "waves" of birds are recorded as reaching the east coast, and also explains the movements after British breeding birds are already nesting ; these later movements are composed of quite different, probably Scandinavian, breeding populations.

T. H. HAWKINS

\section{AFFINITY: A NEW GENETIC PHENOMENON IN THE HOUSE MOUSE}

\section{Evidence from Distant Crosses}

T is generally assumed that at the first meiotio 1 division the orientation of each bivalent towards the poles of the cell is at random, and consequently that (apart from viability disturbances) genetic linkage is the basis of all departures from Mendel's Law of Independent Assortment. Exceptions to random orientation are known in, for example, $S_{\text {Sciara }}{ }^{1,2}$, certain scale insects ${ }^{3}$, the Ascomycete Bombardia lunata ${ }^{4}$, and Drosophila melanogaster ${ }^{5}$. Analogous phenomena in Heteroptera have been described and discussed by Dr. C. D. Darlington ${ }^{6}$.

In the last two cases, the region of the chromosome responsible for the preferential orientation was shown to be the neighbourhood of the centromere, as might in general be expected, since it is the centromere which normally directs the orientation and movement of the chromosome on the spindle.

If the respective centromeres of more than one chromosome simultaneously show non-random segregation, the loci lying on different chromosomes may appear to belong to the same linkage group. The strength of the apparent linkages will depend both on the degree of preferential orientation of the centromeres and on the strength of the true linkages between the loci concerned and their centromeres. Such quasi-linkages will not show the type of arithmetical regularities which characterize true linkage and which reflect the linear order of the linked loci on the same chromosome.

The purpose of this communication is to suggest an interpretation along these lines of anomalous segregation ratios which were obtained by various workers many years ago from distant crosses in the mouse. It is hoped that the hypothesis advanced here will, if confirmed, be of some genetic and evolutionary interest.

The main body of data to be considered resulted from a cross performed by Gates? between a male 'Japanese' waltzer (a domesticated variety of Mus bactrianus) and a female European laboratory mouse (Mus musculus). The phenotypic frequencies in the backcross progeny departed strikingly from Mendelian expectations, as can be seen from the accompanying table. In addition to the marked loci shown, segregation also occurred at the pink-eye locus. But since it made no contribution to the statistical disturbance, the data are presented here after combining the pink-eyed with the non-pink-eyed classes.

PHENOTYPIC RATIOS DERTVED BY GATES FROM AN $M$. musculus $\times$
$M$. bactrianus' CROSS

\begin{tabular}{|c|c|c|c|c|c|}
\hline \multicolumn{4}{|c|}{ 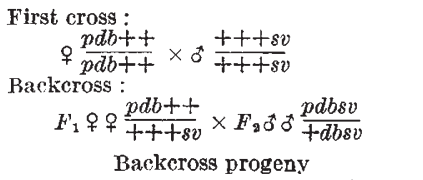 } & \multicolumn{2}{|c|}{$\begin{array}{l}\text { Comparison of } \\
\text { observation with ex- } \\
\text { pectation calculated" } \\
\text { on the basis of "polar" } \\
\text { affinity. Comple- } \\
\text { mentary genotypes } \\
\text { added } \\
\text { observed Expected }\end{array}$} \\
\hline $\begin{array}{l}++s v \\
++s+ \\
+++v \\
++++ \\
+b s v \\
+b s+ \\
+b+v \\
+b++\end{array}$ & $\begin{array}{r}117 \\
77 \\
85 \\
81 \\
77 \\
73 \\
79 \\
59\end{array}$ & $\begin{array}{l}d b++ \\
d b+v \\
d b s+ \\
d b s v \\
d+++ \\
d++v \\
d+s+ \\
d+s v\end{array}$ & $\begin{array}{l}86 \\
85 \\
83 \\
88 \\
90 \\
86 \\
67 \\
56\end{array}$ & $\begin{array}{l}203 \\
162 \\
168 \\
169 \\
167 \\
159 \\
146 \\
115\end{array}$ & $\begin{array}{l}199 \cdot 7 \\
176 \cdot 6 \\
172 \cdot 8 \\
152 \cdot 9 \\
167 \cdot 0 \\
147 \cdot 7 \\
144 \cdot 5 \\
127 \cdot 8\end{array}$ \\
\hline & & & & 1,289 & $1,289 \cdot 0$ \\
\hline
\end{tabular}

$d=$ dilute, $b=$ brown, $\delta=$ pied, $v=$ waltzing

The fit to expectation is very poor. $\chi^{2}{ }_{(15)}$ is $36 \cdot 170$, and if we eliminate the eight degrees of freedom relating to the equivalence of complementary genotypes, we have $\chi_{(7)}^{2}=26.432(P<0.001)$. Gates noted that the ratios were disturbed and also that the single-factor ratios were good. He directed attention to the marked excess of the bactrianus combination of characters, and as an interpretation he postulated an "association system"-_" tendency on the part of the chromosomes to associate together according to parental grouping, thus distorting the theoretical proportions". His meaning is not entirely clear for the following reasons: (1) the parental chromosomes no longer exist as such after crossing-over ; each chromosome enters a gamete as a patchwork of material derived from both parents ; (2) he remarks, "The chromosomes of the female parent, as representative of the fancy mouse, do not seem to group together as strongly as those of the Japanese parent ...". This casts doubt on whether he intended to refer to meiotic phenomena at all; and (3) earlier work to which he refers as exemplifying "association systems" in fact relates to superior viability of non-recombinant gametes in species hybrids, and not to the mode of gamete formation.

Gates's phrase 'association system' did, however, suggest the present hypothesis, which may, in fact, be no more than a development of his intended meaning. It is that, at the first meiotic division in the hybrid, musculus centromeres tend to go to one pole and bactrianus centromeres to the other. Sir Ronald Fisher has suggested to me that the term 'affinity' be adopted for this phenomenon. It could result from an attraction of centromeres of like origin either for each other (which I shall term 'mutual affinity'), or for some polar element of the cell ('polar affinity'). 